\title{
Effects of Mid-winter Snow Depth on Stand Selection by Wolverines, Gulo gulo luscus, in the Boreal Forest
}

\author{
JONATHAN D. WRIGHT ${ }^{1}$ and JESSICA ERNST
}

\author{
Ernst Environmental Services, Box 753, Rosebud, Alberta T0J 2T0 Canada \\ Present address: Box 648, East Coulee, Alberta T0J 1B0 Canada
}

Wright, Jonathan D., and Jessica Ernst. 2004. Effects of mid-winter snow depth on stand selection by Wolverines, Gulo gulo luscus, in the boreal forest. Canadian Field-Naturalist 118(1): 56-60.

Wolverines (Gulo gulo luscus) in a study area in the boreal upland forests of northwestern Alberta and northeastern British Columbia (approximately $57^{\circ} \mathrm{N}$ ) were noted to be limited to upland landscapes, despite abundant food in adjacent lowland landscapes. Snow-tracking suggested that the species was selecting for the densest climax conifer stands for travel in search of food. It was hypothesized that snow depth was a limiting factor for Wolverines in the boreal forest during midwinter, and that they selected for this stand-type because of the buffering effect of this type of canopy on ground snow-depths. A series of snow-depth measurements were collected. Snow depths collected along Wolverine trails were very significantly lower than random snow depths collected under upland canopy $(F=32.84$, df $=1, P<<0.010)$. There was a significant buffering effect on snow depth indicated for upland canopy $(F=11.1, \mathrm{df}=1, P<0.010)$, while adjacent lowland canopy had no significant buffering effect on snow depth $(F=3.45, \mathrm{df}=1, P>0.05)$. Wolverines were hypothesized to be limited to upland landscapes in the study area because of the buffering effect on snow-depth of the stand types found there, and not for reasons of food availability. Climax conifer stands were interpreted as being of high importance to Wolverine survival during winter. Conservation implications include the detrimental effect on Wolverine populations likely to result from current timber harvesting practices in the boreal forest.

Key Words: Wolverine, Gulo gulo luscus, snow depth, boreal forest, stand, landscape, climax, buffering effect, timber harvesting, Alberta, British Columbia.

The Wolverine, Gulo gulo luscus, remains among the least understood of the world's forest mesocarnivores. Recent research focusing on the life history of the species in cordilleran landscapes is beginning to fill knowledge gaps. However, landscape features documented as being of high importance to Wolverines in mountainous regions - for example, the alpine zone (Eric Lofroth, personal communication [see Acknowledgments section for affiliation]) - are unavailable to forest populations.

In the boreal forest, Wolverines are believed to be declining from densities that appear to be lower than in any of the other landscapes in which they occur (Banci 1994). As they are less observable in the forest due to the unbroken forest canopy, Wolverine study in the forest ecoprovinces is an even greater challenge than in alpine habitats. It is therefore not surprising that Banci (1994) has suggested that stand-level and landscape scale "habitat use by Wolverines in forests has not been adequately investigated", and that research is needed to study the "habitat needs of Wolverine in forests, because there is no sound basis for developing habitat management prescriptions at the stand level". In forested areas of the northwest, the Wolverine is the furbearer about which wildlife agencies have the greatest concern (Bill Johnson, personal communication).

There has been agreement among researchers that Wolverine "habitat is probably best defined in terms of adequate year-round food supplies in large, sparsely inhabited wilderness areas, rather than in terms of particular types of topography or plant associations" (Kelsall 1981)*. Seasonal shifts by Wolverine in cordilleran landscapes from the alpine zone in the summer to subalpine forest in the winter have been attributed to the availability of food (Banci 1994), or are thought to be related to avoidance of high temperatures or humans (Hornocker and Hash 1981). While snow depth has been investigated as a limiting factor for Fishers, Martes pennanti (Krohn et al. 1995; Raine 1983), it has not been implicated as a factor affecting habitat selection in the Wolverine.

This paper presents the hypothesis that Wolverines in the boreal forest are limited by mid-winter snow conditions, which in turn affects stand, and in this case, landscape selection.

\section{Methods}

Snow tracking is being increasingly recognized as a reputable scientific tool in wildlife studies, management and conservation, with efforts being made to establish standardized terminology, institute university courses on the subject, and to establish networks of trackers throughout the North American continent (Rezendes 1999; Zielinski and Kucera 1995). Snow tracking may be the only practical way of learning details of Wolverine habits and habitat use, as such details are not adequately provided by radio-telemetry studies (John Krebs, personal communication; Eric Lofroth, personal communication). 
Wolverine and other furbearer activities were monitored during three winter seasons (1997-2000) utilizing snow-tracking methods. Approximately $34000 \mathrm{~km}$ were traveled by truck, snowmobile, cross-country skis and on foot, in search of furbearer tracks, with an emphasis on locating Wolverines. The tracking efforts covered approximately $1100 \mathrm{~km}^{2}$ in the region of the border country of Alberta and British Columbia known as "Chinchaga" (after the Chinchaga River), at approximately $57^{\circ}$ north latitude. The tracking area offered conditions especially conducive to this type of study, in that the landscape could be conveniently divided into distinct upland and lowland components. These components offered markedly different and readily divisible stand characteristics as a result of the "Great Chinchaga Fire" which blanketed the area during the 1950s (Don Williams, personal communication), burning all but some upland ridges. Fifty years following the fire, two distinct forest types predominate: early-to-mid seral second-growth of predominantly aspen or pine in the lowlands, with more limited late-seral, climax or "over-mature" stands predominated by White and Black spruce (Picea spp.), and mostly dead and dying Populus spp. in the uplands. The lowland forest may be further characterized as forming a mosaic broken by broad expanses of relatively open Black spruce fen and willow (Salix sp.) muskeg. The upland forest cover is by comparison more continuous.

The area is thoroughly criss-crossed by open linear corridors at varying stages of regeneration that were cleared to conduct seismology work, and have been implicated in possible predator/prey imbalances. Seismology work and subsequent oil and gas exploration and extraction activities have been traditional in the area since the 1950s (Brody 1981). The area is experiencing a surge of such activities at present, and there was virtually no segment of the area covered in tracking Wolverines that was not impacted by these activities at some point during the three winter seasons.

Moose (Alces alces) reach some of their highest densities in North America in the area (Brody 1981), being most heavily distributed in the lowlands, and frequent in the uplands. Groups of Woodland Caribou (Rangifer tarandus caribou) are frequent at low densities in the lowlands. These are the only two common ungulate species in the region, and they offer a generous prey-base for the area's healthy Grey Wolf (Canis lupus) population, whose kills in turn offer a ready food source for the infrequent Wolverines.

When Wolverine tracks were located, the individuals were fore-tracked (older trails) or back-tracked (fresh trails) in order to gain insights into important and little-known details of the creature's use of the boreal forest, including landscape and stand use. Tracks were accessed in the morning by snowmobile or truck, and followed on foot as long as daylight permitted, with the exception of one overnight excursion conducted in order to assess advantages and disadvantages to the tracking process of remaining in situ. Pertinent details of the Wolverine's behavior were logged in field notebooks during the tracking event as well as being photographically documented.

Snow depth measurements (in centimetres) were taken over a time frame of approximately 1 week, characterized by below-freezing temperatures, between periods of snowfall. Snow depths were taken at locations determined using random numbers generated by a portable computer (calculator). The number indicated the number of paces to be taken on the ground, either within a grid-square (random snow depths), or along a Wolverine or Lynx (Lynx canadensis) trail, at which point a snow-depth was taken.

The following snow-depth data were recorded:

- Ten random depths on open upland sites (to quantify "non-buffered" upland snow depth) with a grid-cell size of $1 \mathrm{~km}^{2}$;

- 27 random depths in forested upland sites ("buffered" upland depths) with a grid-cell size of $1 \mathrm{~km}^{2}$;

- Ten random depths on open lowland sites (to quantify non-buffered lowland snow depth) with a grid-cell size of $1 \mathrm{~km}^{2}$;

- 25 random depths on forested lowland sites (buffered lowland depths) with a grid-cell size of $1 \mathrm{~km}^{2}$;

- 46 random depths along documented Wolverine trails at random paced intervals;

- 29 random depths along Lynx trails (for comparison purposes) at random paced intervals.

The following comparisons were made utilizing ANOVA tests of significance:

- Snow depths along Wolverine trails versus random forested upland snow depths;

- Random forested upland snow depths versus random open upland snow depths (= "buffering effect" of upland canopy on snow depth);

- Random forested lowland snow depths versus random open lowland snow depths (= buffering effect of lowland canopy on snow depth);

- Snow depths along Lynx trails versus random forested lowland snow depths (for comparison purposes).

Crusting of snow typically occurs in the area of this study during late winter to early spring, and occasionally in late fall, depending on temperatures. Crustless (powder) conditions are the norm in this region for the majority of the snow season. Snow conditions were noted as being of a crustless nature during the collection of this data.

Wolverine reactions to linear corridors such as access roads and seismic lines were documented as encountered, with special attention being paid to the effect that snow conditions on the corridors (compacted versus undisturbed) had on Wolverine response.

Efforts were made to locate Wolf kills in both representative landscapes in order to monitor such important food sources for utilization by Wolverines.

\section{Results}

Wolverine tracks were located on ten occasions over three winters (for a mean of one Wolverine track en- 
countered per $3400 \mathrm{~km}$ of searching). Thirteen separate tracking events resulted, totaling 20 linear $\mathrm{km}$ of off-corridor (forest) tracking, or 26.6 total off-corridor km using Magoun's (1985) estimate of adding $33 \%$ to arrive at non-linear distance traveled. Wolverines were tracked for an additional $12.3 \mathrm{~km}$ on linear corridors offering conditions of compacted snow, for a total estimated tracking distance of $38.9 \mathrm{~km}$.

Seven Wolf kills (Moose) were located, two in the upland landscape and five in the lowland landscape. These kills were monitored for Wolverine use. An additional road-killed Moose in the lowland landscape was monitored for Wolverine use. Of these, Wolverine were documented as utilizing one of the upland Wolf kills.

Despite frequent available food in the lowland landscape, Wolverine tracks were located only in the upland landscape. Wolverines were revealed to have remained in the uplands throughout the tracking events.

One Wolverine tracked was noted to have traveled through a burned-over upland area regenerating to Lodgepole Pine (Pinus contorta). The second-growth pine formed a low (approximately three-metre), dense canopy. Heavy use of the burn by Snowshoe Hares (Lepus americanus), provided compacted trails on which the Wolverine traveled through this second-growth.

Wolverines often encountered linear corridors during their travels. Wolverine diverged from their line-oftravel under the forest canopy to travel on $100 \%$ of the linear corridors encountered that offered conditions of compacted snow $(n=17)$, for distances ranging from $3-3000 \mathrm{~m}$. Wolverines did not travel on any of the corridors encountered that had undisturbed snow cover $(\mathrm{n}=16)$, choosing instead the most direct route across in $100 \%$ of instances noted.

There were two instances where an individual Wolverine paralleled an undisturbed east-west corridor from just within the south-facing edge of the canopy. The individual crossed the respective corridors involved to select the south-facing aspect for travels of $470 \mathrm{~m}$ and $30 \mathrm{~m}$, before diverging deeper into forest. Exposure to the sun had acted in concert with the buffering effect of the canopy to reduce snow depth from $32 \mathrm{~cm}$ on the corridor, to $4-11 \mathrm{~cm}$ under the canopy's edge.

Snow depths along routes selected for travel by Wolverines were significantly less than random snow depths under the upland canopy $(F=32.84, \mathrm{df}=1, P$ $<0.010)$.
Random upland snow depths under the canopy were significantly less than snow depths in open upland areas $(F=11.1, \mathrm{df}=1, P<0.010)$, whereas random lowland snow depths under canopy were not significantly different from snow depths in open lowland sites $(F=$ $3.45, \mathrm{df}=1, P>0.05)$.

Snow-depths along routes selected for travel by Lynx were not significantly different from random snow depths under the lowland canopy, where Lynx data were collected $(F=2.86, \mathrm{df}=1, P>0.05)$.

When Wolverine tracks were discovered exiting the forest onto access routes, the Wolverines involved had invariably been traveling through dense to extremely dense coniferous cover. While subsequent travel on compacted linear corridors would frequently take a Wolverine through a variety of stand types, the Wolverines invariably selected similarly dense coniferous cover for re-entry into the forest. Within the forest, Wolverines were frequently, even continuously, observed to alter their direction of travel $(n=29)$ to select for routes that offered an even slightly denser canopy cover (increased buffering effect on snow). Of the random upland sites, $70 \%$ were estimated to represent a similar cover type to that selected by Wolverines for travel, as compared to $20 \%$ of random lowland sites.

\section{Discussion}

Popular and even scientific literature of past decades reflected the level of misconception surrounding the Wolverine. The Wolverine was seen as unique among wildlife in being best adapted to survive during the harshest months, to the point of finding winter a season of ease (Rausch and Pearson 1972). The animal's adaptations to a winter landscape were provided as evidence of this: the dense, luxurious coat (which may give the illusion of good underlying physical condition in winter); the enormous, well-haired "snowshoe" feet cited as enabling the animal to coast effortlessly on top of deep snow; the preference for the harshest wilderness areas. In fact, in an ongoing study in the foothills of northern British Columbia, Wolverines in winter were often found upon examination to be in a state of energetic stress approaching thresholds of starvation (Don Reid, personal communication); a large percentage of dissected Wolverines have empty gastrointestinal tracts (Banci 1994). Unlike such sympatric predators as Martens (Martes americana), and coloured foxes (Vulpes vulpes), Wolverines are too large to survive on small prey (Banci 1994), and must therefore wander widely, as indicated in all studies, in search

TABLE 1: Comparison of random snow depths

\begin{tabular}{lccc}
\hline \hline & Wolverine Trails & Random Lowland Locations & Lynx Trails \\
\hline Range & $13-47 \mathrm{~cm}$ & $23-52 \mathrm{~cm}$ & $17-54 \mathrm{~cm}$ \\
Mean & $31 \mathrm{~cm}$ & $40 \mathrm{~cm}$ & $36 \mathrm{~cm}$ \\
Standard Deviation & 9.03 & 7.5 & 8.2 \\
\hline \hline
\end{tabular}


of less reliable yet more bountiful sources of food such as large ungulate carrion.

While recent research is presenting a different picture of Wolverines and their habits, apparent contradictions still abound. One of the more notable of the apparent contradictions in Wolverine behavior is addressed by this paper: Why do Wolverines select for wide-open landscapes in some parts of their range and the densest of cover in other areas such as the boreal forest? During the tracking of Wolverines in the boreal forest at Chinchaga, patterns of behavior became apparent. The species limited itself to the upland landscape despite abundant food in the lowlands, contradicting literature which suggested that wilderness conditions and a ready supply of food governed the Wolverine's presence or absence, rather than specific landscape and stand features (Kelsall 1981*; Banci 1994). The observation that Wolverines in the study area were limiting themselves to a specific landscape (at least during winter) was supported by conversations with the area's fur trappers and wildlife agents, who noted that:

(1) over many decades of trapper experience in the Chinchaga area, Wolverines were encountered in heavily timbered upland terrain (Les Sharp, personal communication);

(2) in a winter trapper's experience over 13 years on a lowland landscape trapline adjacent to uplands where Wolverines were tracked during this study, not a single Wolverine was caught, nor tracks ever detected (Larry Smith, personal communication).

(3) in other lowland traplines in the area with long traditions of use none were recalled to have ever yielded Wolverine pelts (Bill Johnson, personal communication).

During the tracking efforts, it became quickly apparent to me that the Wolverines were continuously selecting, where feasible, for the path of least snow cover. When faced with even a slight thinning of the forest canopy (= deeper snow conditions), the animals were observed to have paused, selected the densest alternative timber, and altered their route to follow this "path of least resistance" in terms of snow depth. The Wolverines would only cross such openings if:

(1) a compacted Showshoe Hare trail crossed the deeper snow, which they would then select;

(2) alternative routes were not available without extensive detour, in which case the Wolverine would cross the deeper snow over the shortest straight-line path, usually at a walking gait.

Wolverines in the area seemed to favor a " $2 \times$ " or "3×" lope (Zielinski and Kucera 1995) when less impeded by snow, suggesting that this was their most efficient gait in terms of energy expenditure versus distance traveled. They would immediately switch to a less efficient walk, however, when faced with unavoidable stretches of deeper snow.

In comparison, Lynx were observed not to avoid deeper snow, readily crossing open areas of the deepest snow conditions, as encountered. This is supported not only by the snow depth data, which showed Lynx (in direct contrast with Wolverine) to have selected paths of insignificantly less snow depth, but also by the fact that Lynx were abundantly found in the lowland landscape where the buffering effect of the forest canopy was demonstrated to be insignificant.

Wolverines traveling together did so single-file for an estimated $95 \%$ of the distance traveled, traveling in tandem only along ridges where snow cover was negligible. It would be interesting to discover if social travel in this species represents a survival strategy, and if the individuals involved alternate as lead-individual.

That Wolverines at Chinchaga were not selecting the densest canopy conditions in order to avoid detection by man or predators is obvious for the following reasons:

(1) In $100 \%$ of cases, they followed open linear corridors offering compacted snow conditions when encountered (including winter roads up to $18 \mathrm{~m}$ wide; freshly opened seismic lines; snowmobile trails; all-terrain vehicle tire tracks; wind-swept ice on creek-beds bisecting open muskeg; compacted otter runways on open creek beds) for travel of distances up to $3 \mathrm{~km}$;

(2) Wolverines are more abundant on the open tundra (characterized by hard-crusted snow conditions) than they are in the forest (Don Reid, personal communication; Banci 1994);

(3) Wolverines seem to prefer the open alpine zones during snow-free seasons in cordilleran landscapes (Whitman et al. 1986; Banci 1994; Don Reid, personal communication; Eric Lofroth, personal communication).

The hypothesis presented by this paper is that Wolverines in the mid-winter boreal forest are limited by snow conditions. Conifer-dominated climax stand types offer the highest buffering effect on snow conditions underfoot. In this study area, such stand-types are only found extensively in upland landscapes, which accounts for the absence of Wolverines in the lowlands, despite abundant food there. Wolverines travel great distances in search of unpredictable food (Banci 1994) while under conditions of energetic stress, necessitating that they pay the strictest attention to energy expenditure while traveling. To travel in conditions of deep powder (unbuffered) snow is to increase risk of starvation, and so such conditions are avoided where alternatives exist. While the relatively enormous feet of the Wolverine, providing low foot loads of $22 \mathrm{~g} / \mathrm{cm}^{2}$ (Knorre 1959) are of great advantage when crusts begin to form (Eric Lofroth, personal communication), they have little effect in the midwinter powder snows of the northwest characterizing this study, as indicated by shifts to an inefficient walking gait in deep, midwinter snow. It is further suggested here that the size of the Wolverine's feet, rather than being an indication of their level of mastery of winter conditions, is instead just the opposite, an adaptation indicative of their extreme level of sensitivity to snow depths as a result of specialized foraging strategies combined with relatively large body size leading to conditions of energetic stress. While one could argue that Lynx, with their equally large feet and specialized foraging strategies, 
should therefore show a similar sensitivity to snow depths not indicated in this study, it should be remembered that the Lynx data herein were collected during years of high hare numbers. Perhaps during the low hare cycle, Lynx must also become more sensitive to snow depths.

\section{Conclusions}

During midwinter, Wolverines in the boreal upland forests of northwestern Alberta and northeastern British Columbia demonstrate preferences at the stand level and landscape scale that are apparently unrelated to food availability, consistently selecting for stand types that offer the greatest available buffering effect on ground snow depth.

Wolverines require the type of boreal forest habitat considered optimum for Martens, the species with which they may be considered most highly sympatric. However, Wolverines appear to be even more dependent on climax conifer forests during winter than are Martens. Climax conifer cover appears to be of high importance to Wolverines in the boreal forest because of the buffering effect this stand type has on snow depth.

Forest practices that remove climax growth may create conditions that are not conducive to Wolverine conservation. As current logging practices in the boreal forest are geared towards precisely this type of stand removal, timber harvesting may be a key factor in apparent population declines. Conditions following removal of climax cover may not become favorable again for Wolverine habitation for many decades (Don Williams, personal communication). The situation may be improved in the case of immediate regeneration to Pinus spp., however, with a minimum estimated lapse of 20 years (several Wolverine generations) before conditions become again conducive to Wolverine travel, if not other life history components of this species. Efforts should be made to preserve linkages of climax conifer cover between more extensive areas of intact climax forest habitat.

\section{Acknowledgments}

Funding, accommodations, and ongoing support for this project were provided by Pioneer Natural Resources Canada Inc., to whom the authors are very deeply grateful. We would also like to thank the following (in order they appear in text) for their personal communications: Eric Lofroth, British Columbia Ministry of Environment, Lands and Parks, Victoria, British Columbia; Bill Johnson, Alberta Environment, Peace River, Alberta; John Krebs, Columbia Basin
Fish \& Wildlife Compensation Program, Nelson, British Columbia; Don Williams, Alberta Environment, Manning, Alberta; Don Reid, British Columbia Ministry of Environment, Lands and Parks, Smithers, British Columbia; and the late Les Sharp, as well as Larry Smith, fur-trappers in the Chinchaga region of Alberta.

\section{Documents Cited (marked with * in text)}

Kelsall, J. P. 1981. Status report on the Wolverine, Gulo gulo, in Canada in 1981. (Committee on the Status of Endangered Wildlife in Canada (COSEWIC), Ottawa, Ontario. 47 pages.

\section{Literature Cited}

Banci, V. 1994. Wolverine. Pages 99-127 in American marten, Fisher, Lynx and Wolverine in the western United States. Edited by L. F. Ruggiero, K. B. Aubry, S. W. Buskirk, L. J. Lyon and W. J. Zielinski. USDA Forest Service General Technical Report RM-254.

Brody, H. 1981. Maps and dreams; Indians and the British Columbia frontier. Douglas \& McIntyre. Vancouver, British Columbia, and Toronto, Ontario.

Hornocker, M. G., and H. S. Hash. 1981. Ecology of the Wolverine in northwestern Montana. Canadian Journal of Zoology 59: 1286 - 1301.

Knorre, E. P. 1959. Ecology of the elk. In Transactions of the Pechora-Ilych State Game Preserve by G. A. Novikov. Translated by The Canadian Wildlife Service 1966. 3895. (7): 324 pages.

Krohn, W. B., K. D. Elowe, and R. B. Boone. 1995. Relations among Fishers, snow and martens: development and evaluation of two hypotheses. The Forestry Chronicle 71(1): 97-105.

Magoun, A. J. 1985. Population characteristics, ecology, and management of Wolverines in northwestern Alaska. Ph. D. thesis, University of Alaska, Fairbanks, Alaska. 197 pages.

Raine, R. M. 1983. Winter habitat use and responses to snow-cover of Fisher (Martes pennanti) and marten (Martes americana) in southeastern Manitoba. Canadian Journal of Zoology 61: 25-34.

Rausch, R. L., and A. M. Pearson. 1972. Notes on the Wolverine in Alaska and the Yukon Territory. Journal of Wildlife Management 36: 249-268.

Rezendes, P. 1999. Tracking \& the art of seeing; how to read animal tracks and sign. Firefly Books, Willowdale, Ontario. 336 pages.

Whitman, J. S., W. B Ballard, and C. L. Gardner. 1986. Home range and habitat use by Wolverines in southcentral Alaska. Journal of Wildlife Management 50: 460462.

Zielinski, W. J., and T. E. Kucera. 1995. American Marten, Fisher, Lynx, and Wolverine: survey methods for their detection. USDA General Technical Report PSW-GTR157.

Received 19 July 2001

Accepted 26 May 2004 